\title{
Outcome after PSMA-PET/CT-based salvage radiotherapy for nodal recurrence after radical prostatectomy
}

\author{
Paul Rogowski ${ }^{1}$ (1) Christian Trapp ${ }^{1} \cdot$ Rieke von Bestenbostel $^{1} \cdot$ Chukwuka Eze $^{1} \cdot$ Ute Ganswindt $^{2} \cdot$ Minglun $\mathrm{Li}^{1}$. \\ Marcus Unterrainer ${ }^{3,4} \cdot$ Mathias J. Zacherl ${ }^{4} \cdot$ Harun Ilhan ${ }^{4}$. Leonie Beyer ${ }^{4} \cdot$ Alexander Kretschmer $^{5}$. \\ Peter Bartenstein ${ }^{4} \cdot$ Christian Stief $^{5}$. Claus Belka ${ }^{1,6} \cdot$ Nina-Sophie Schmidt-Hegemann ${ }^{1}$
}

Received: 21 July 2021 / Accepted: 5 September 2021 / Published online: 10 October 2021

(c) The Author(s) 2021

\begin{abstract}
Purpose Nodal recurrent prostate cancer (PCa) represents a common state of disease, amenable to local therapy. PSMA-PET/ CT detects PCa recurrence at low PSA levels. The aim of this study was to evaluate the outcome of PSMA-PET/CT-based salvage radiotherapy (sRT) for lymph node (LN) recurrence.

Methods A total of 100 consecutive patients treated with PSMA-PET/CT-based salvage elective nodal radiotherapy (sENRT) for LN recurrence were retrospectively examined. Patients underwent PSMA-PET/CT scan due to biochemical persistence (bcP, 76\%) or biochemical recurrence (bcR, 24\%) after radical prostatectomy (RP). Biochemical recurrence-free survival (BRFS) defined as PSA < post-RT nadir $+0.2 \mathrm{ng} / \mathrm{ml}$ and distant metastasis-free survival (DMFS) were calculated using the Kaplan-Meier method and uni- and multivariate analysis was performed.

Results Median follow-up was 37 months. Median PSA at PSMA-PET/CT was $1.7 \mathrm{ng} / \mathrm{ml}$ (range 0.1-40.1) in patients with bcP and $1.4 \mathrm{ng} / \mathrm{ml}$ (range $0.3-5.1$ ) in patients with bcR. PSMA-PET/CT detected 1, 2, and 3 or more LN metastases in 35\%, $23 \%$, and $42 \%$, respectively. Eighty-three percent had only pelvic, $2 \%$ had only paraaortic, and $15 \%$ had pelvic and paraaortic LN metastases. Cumulatively, a total dose converted to EQD2 1.5 Gy of 66 Gy (60-70 Gy) was delivered to the prostatic fossa, $70 \mathrm{~Gy}$ (66-72 Gy) to the local recurrence, if present, 65.1 Gy (56-66 Gy) to PET-positive lymph nodes, and 47.5 Gy (42.4-50.9 Gy) to the lymphatic pathways. Concomitant androgen deprivation therapy (ADT) was administered in $83 \%$ of patients. One-, 2-, and 3-year BRFS was 80.7\%, 71.6\%, and 65.8\%, respectively. One-, 2-, and 3-year DMFS was 91.6\%, $79.1 \%$, and $66.4 \%$, respectively. In multivariate analysis, concomitant ADT, longer ADT duration $(\geq 12$ vs. $<12$ months $)$ and LN localization (pelvic vs. paraaortic) were associated with improved BRFS and concomitant ADT and lower PSA value before sRT ( $<1 \mathrm{vs.}>1 \mathrm{ng} / \mathrm{ml}$ ) with improved DMFS, respectively. No such association was seen for the number of affected lymph nodes.

Conclusions Overall, the present analysis shows that the so far, unmatched sensitivity and specificity of PSMA-PET/CT translates in comparably high BRFS and DMFS after PSMA-PET/CT-based sENRT for patients with PCa LN recurrence. Concomitant ADT, duration of ADT, PSA value before sRT, and localization of LN metastases were significant factors for improved outcome.
\end{abstract}

Keywords Prostate cancer · Nodal recurrence $\cdot$ PSMA PET/CT $\cdot$ Salvage radiotherapy $\cdot$ Nodal radiotherapy $\cdot$ ENRT

Paul Rogowski and Christian Trapp contributed equally to this work.

This article is part of the Topical Collection on OncologyGenitourinary

Paul Rogowski

Paul.Rogowski@med.uni-muenchen.de

Extended author information available on the last page of the article

\section{Background}

About one-third of patients treated with radical prostatectomy (RP) for prostate cancer (PCa) experience biochemical persistence $(\mathrm{bcP})$ or biochemical recurrence $(\mathrm{bcR})[1$, 2]. In this situation, postoperative radiotherapy (RT) is a well-established treatment option even though there are still some ongoing questions. Surveys among radiation oncologists show a wide variety of treatment protocols $[3$, 
4]. In particular, timing of RT, dose prescription, treatment volume, use of concomitant androgen deprivation therapy (ADT), and the choice of pre-treatment imaging are essential topics still under discussion. Regarding the last point, prostate-specific membrane antigen positron emission tomography/computed tomography (PSMA-PET/CT) prevailed against choline PET/CT and fluciclovine PET/CT. It is therefore viewed as the gold standard for staging in this situation and is recommended by EAU guidelines [5]. PSMA-PET/CT is known to have a high positive predictive value [6] and to detect PSMA-positive lesions already at low prostate-specific antigen (PSA) levels thus leading to a high amount of treatment modifications [7-9]. Furthermore, studies evaluating PSMA-PET/CT staging in different clinical situations showed a high efficacy in patients with bcR and bcP with a PSMA positivity rate of more than $40 \%$ and more than $60 \%$, respectively $[10,11]$. Overall, positive results in PSMA-PET/CT staging are a good predictor for failure-free survival in patients with a biochemical relapse after RP [12]. Often, PSMA-PET/CT imaging reveals lymph node (LN) recurrence in patients with bcP or bcR [13-15]. Also in this subset of patients, RT represents one of the mainstays of treatment even though the radiotherapeutic approach (stereotactic body radiotherapy (SBRT) vs. elective nodal radiotherapy (ENRT)), the role of concomitant $\mathrm{ADT}$ and the therapeutic consequences of paraaortic LN involvement are still to be evaluated. As shown in mostly retrospective analyses so far, ENRT seems to be an effective treatment strategy with rare side effects [16-19]. Most of these analyses included mostly patients prior to the PSMAPET/CT era and so data on PSMA-PET/CT-based salvage ENRT (sENRT) for LN recurrence after RP are currently still sparse. Thus, this retrospective study reports on the outcome after PSMA-PET/CT-based sENRT in patients with pelvic and/or paraaortic LN recurrence. Furthermore, this analysis aims to investigate the benefit of additional ADT in patients with LN recurrence in order to facilitate patients' counseling.

\section{Methods}

\section{Patient population}

Patients consecutively undergoing PSMA-PET/CT-based sENRT for LN recurrence at the University Hospital, LMU Munich, were considered for this analysis and were retrospectively analyzed. All patients had histologically confirmed PCa and were referred for SRT after RP due to persistent or rising PSA. No patient had prior RT to the prostate or the prostate bed. All patients provided written informed consent to undergo PSMA PET/CT. An interdisciplinary tumor board approved the treatment indication. Patients with M1a disease limited to the lumboaortic region below the renal arteries were included, while patients with $\mathrm{M} 1 \mathrm{~b} /$ M1c disease were excluded. This retrospective analysis was performed in compliance with the principles of the Declaration of Helsinki and its subsequent amendments [20] and was approved by the local Ethics Committee of the Medical Faculty (approval number 19-361).

\section{PSMA ligand and PET/CT imaging protocol}

Pretreatment imaging was performed with ${ }^{68} \mathrm{Ga}$ - or ${ }^{18} \mathrm{~F}$-labeled PSMA-PET/CT in $75 \%\left({ }^{68} \mathrm{Ga}\right.$-PSMA-11) and $25 \%\left({ }^{18}\right.$ F-PSMA-1007) of patients, respectively. Radiolabeling was performed according to good clinical practice as described previously [21, 22]. A Siemens Biograph 64 or GE Discovery 690 PET/CT scanner was used for PSMAPET/CT imaging. Phantom studies based on the National Electrical Manufacturers Association NU2-2001 standard were conducted in Munich to allow for pooling of the different scanner results. At the time of the PET scan, a contrast-enhanced diagnostic CT $(120 \mathrm{kV}, 100-400 \mathrm{mAs}$, dose modulation) or a low-dose CT (120 kV, $25 \mathrm{mAs})$ for attenuation correction (depending on previous CT scans and contraindications) was performed. PSMA-PET/CT scans were acquired approx. $60 \mathrm{~min}$ after intravenous injection of the ${ }^{68} \mathrm{Ga}-{ }^{18} \mathrm{~F}-\mathrm{PSMA}$-ligand complex. Barring any contraindications, patients receiving PSMA-PET/CT were administered $20 \mathrm{mg}$ furosemide at the time of tracer injection to avoid bladder activity and to reduce radiation exposure.

\section{Image analysis}

PET/CT was interpreted by one nuclear medicine physician and one radiologist in the sense of a clinical report-based analysis. Both readers had more than 5 years of PET/CT experience. Location of lesions was each determined by CT. PET-positive lesions were visually identified by ${ }^{68} \mathrm{Ga}-{ }^{18} \mathrm{~F}$ PSMA uptake above background and not associated with the physiologic uptake [23].

\section{Radiotherapy treatment and follow-up}

All patients were treated with intensity modulated RT (IMRT) or volumetric arc therapy (VMAT) with 5 fractions per week. Image-guided RT (IGRT) was performed with cone-beam CT (2-5 times per week). RT dose regimens were normo- or slightly hypofractionated with a simultaneous integrated boost (SIB) to the PET-positive lesions. Target delineation was performed according to the Radiation Therapy Oncology Group (RTOG) atlas for salvage PCa and for pelvic LN delineation and was extended in case PSMAPET/CT revealed pathological LN outside the recommended clinical target volume [24]. ADT was recommended to 
all patients for 24-36 months, but the duration could be adjusted at the discretion of the treating urologist depending on comorbidities, side effects, and patient's preference. Follow-up examination was first carried out 3 months after RT and then every six to 12 months.

\section{Endpoints and statistical analysis}

The primary endpoint was biochemical recurrence-free survival (BRFS) defined as PSA < post-RT nadir $+0.2 \mathrm{ng} / \mathrm{ml}$. The secondary endpoint was distant metastasis-free survival (DMFS). Survival data were calculated as time from last day of RT to biochemical progression/diagnosis of distant metastasis or to the date of the last follow-up. Statistical analyses were conducted using IBM-SPSS $®$ version 26.0. Survival analyses were calculated using the Kaplan-Meier method and compared using the log-rank test. For multivariate analysis, cox regression analysis was performed including potential covariates such as ISUP score, initial tumor stage, initial nodal stage, number of PSMA PET-positive LN metastases, PSMA PET-positive LN localization, presence of PSMA PET-positive local recurrence, PSA before sRT, concomitant ADT, duration of ADT, and PSA persistence vs. PSA recurrence. A $p$-value $<0.05$ was considered significant.

\section{Results}

Between April 2014 and December 2019, 100 patients with bcP $(76 \%)$ or bcR (24\%) after RP underwent PSMA-PET/ CT-based RT for LN recurrence. Median follow-up was 37.6 months. Patient characteristics are shown in Table 1. Initial tumor stage was pT2 in $21 \%$ and $\geq$ pT3 in $79 \%$. Initial nodal stage was pN0 in most patients (54\%). Fifty-two percent had positive surgical margins after RP. Most patients had International Society of Urological Pathology (ISUP) score 4 or $5(61 \%)$. The median PSA-Nadir after RP was $0.6 \mathrm{ng} / \mathrm{ml}$.

The median interval between surgery and bcR was 22.5 months. The median PSA at the time of the PSMAPET/CT was $1.7 \mathrm{ng} / \mathrm{ml}$ (range $0.1-40.1 \mathrm{ng} / \mathrm{ml}$ ) in patients with bcP and $0.6 \mathrm{ng} / \mathrm{ml}$ (range $0.3-5.1 \mathrm{ng} / \mathrm{ml}$ ) in patients with bcR. PSMA-PET/CT showed one, two, and three or more LN metastases in 35\%,23\%, and $42 \%$, respectively. Eighty-three percent had pelvic only, $2 \%$ had paraaortic only, and $15 \%$ had pelvic and paraaortic LN metastases.

Treatment characteristics are shown in Table 2. Median RT doses converted to EQD2 equivalent doses using an $\alpha / \beta$ ratio of 1.5 Gy were 47.5 Gy (range $42.4-50.9 \mathrm{~Gy}$ ) to the pelvic lymphatic drainage pathways, 66 Gy (range 60-70 Gy) to the prostatic fossa, and if present, 70 Gy (66-72 Gy) to PSMA PET-positive local recurrence.
PET-positive lymph nodes received a SIB of median 65.1 Gy (range 56-66 Gy). ADT was recommended to all patients but refused by $17 \%$, resulting in concomitant administration in $83 \%$ of patients. The duration of the ADT was less than 6 months, 6 to 12 months, 12 to 24 months, and more than 24 months in $18 \%, 22 \%, 17 \%$, and $22 \%$ of the patients, respectively. Eighty percent of patients had no ADT at last follow-up and time between end of ADT and last follow-up was in median 31.9 months.

Median BRFS was not reached. One-, 2-, and 3-year BRFS was $80.7 \%, 71.6 \%$, and $65.8 \%$, respectively (Fig. 1). In those patients without ADT at last follow-up (80/100), 1-, 2 -, and 3-year BRFS was $77.6 \%, 67.6 \%$, and $61.5 \%$, respectively. Median DMFS was not reached. One-, 2-, and 3-year DMFS was $91.6 \%, 79.1 \%$, and $66.4 \%$, respectively (Fig. 2). In patients without ADT at last follow-up, 1-, 2-, and 3-year DMFS was $90.9 \%, 76.9 \%$, and $63.6 \%$. Tables 3 and 4 show the results of the univariate and multivariate analyses. Concomitant ADT was significantly associated with improved BRFS and DMFS whereas the duration of ADT treatment ( $<12$ vs. $\geq 12$ months) was only significantly associated with BRFS but not with DMFS. A PSA value $<1 \mathrm{ng} / \mathrm{ml}$ before sRT was significantly associated with better BRFS (only in univariate but not in multivariate analysis) and DMFS. Paraaortic LN localization was associated with worse BRFS in multivariate analysis.

\section{Discussion}

The present analysis shows a high 2- and 3-year BRFS of $72 \%$ and $66 \%$ and a high 2- and 3-year DMFS of $79 \%$ and $66 \%$ after PSMA-PET/CT-based sENRT for such an oncologically unfavorable group of patients with $\mathrm{PCa} \mathrm{LN}$ recurrence with thus a potentially second chance of cure [25]. To account for the bias of an ongoing ADT on these endpoints, we assessed survival data separately for $80 / 100$ patients without ongoing ADT at last follow-up. In these patients, 2 - and 3-year BRFS was 68\% and 62\%, and 2- and 3-year DMFS was $77 \%$ and $64 \%$, respectively. Multivariate analysis reconfirmed the use of concomitant ADT, the duration of ADT, the PSA level before sRT and the LN localization as significant factors for an improved outcome.

Overall, these results are very promising in comparison to other studies reporting on PET/CT based ENRT with SIB to macroscopic LN metastases. In 2017, Fodor et al. published a retrospective analysis of 81 patients with $\mathrm{LN}$ recurrence and reported a 3-year BRFS of $42 \%$ and a 3-year clinical relapse-free survival of $62 \%$. The main differences to the current analysis are a visibly more heterogenous cohort with more than half of the patients with previous RT and even inclusion of patients with mediastinal lymph nodes as well as the use of choline PET/CT as staging prior to RT 
Table 1 Patient characteristics

\begin{tabular}{|c|c|}
\hline Patients, $n$ & 100 \\
\hline Age, median (range) & $72(46-82)$ \\
\hline \multicolumn{2}{|l|}{ Initial tumor stage, $n(\%)$} \\
\hline pT2a & $1(1 \%)$ \\
\hline pT2c & $20(20 \%)$ \\
\hline pT3a & $25(25 \%)$ \\
\hline pT3b & $51(51 \%)$ \\
\hline pT4 & $3(3 \%)$ \\
\hline \multicolumn{2}{|l|}{ Initial nodal stage, $n(\%)$} \\
\hline $\mathrm{pN} 0$ & $54(54 \%)$ \\
\hline $\mathrm{pN} 1$ & $42(42 \%)$ \\
\hline $\mathrm{pNx} / \mathrm{cN} 0$ & $2(2 \%)$ \\
\hline Unknown & $2(2 \%)$ \\
\hline Positive surgical margins, $n(\%)$ & $52(52 \%)$ \\
\hline \multicolumn{2}{|l|}{ ISUP score, $n(\%)$} \\
\hline 1 & $2(2 \%)$ \\
\hline 2 & $12(12 \%)$ \\
\hline 3 & $25(25 \%)$ \\
\hline 4 & $18(18 \%)$ \\
\hline 5 & $43(43 \%)$ \\
\hline PSA at RP (ng/ml), median (range) & $13.9(0.05-427)$ \\
\hline Postoperative PSA (ng/ml), median (range) & $0.6(0.0-40.1)$ \\
\hline Patients with $\mathrm{bcP} / \mathrm{bcR}, n(\%)$ & $76(76 \%) / 24(24 \%)$ \\
\hline Time between RP and bcR (month), median (range) & $22.5(2-148)$ \\
\hline PSA at PSMA-PET/CT (ng/ml), median (range) & $1.4(0.1-40.1)$ \\
\hline PSA at PSMA-PET/CT in patients with bcP (ng/ml), median (range) & $1.7(0.1-40.1)$ \\
\hline PSA at PSMA-PET/CT in patients with bcR (ng/ml), median (range) & $0.6(0.3-5.1)$ \\
\hline \multicolumn{2}{|l|}{ Number of lymph node metastases on PSMA-PET/CT, $n(\%)$} \\
\hline 1 & $35(35 \%)$ \\
\hline 2 & $23(23 \%)$ \\
\hline$\geq 3$ & $42(42 \%)$ \\
\hline Patients with local recurrence on PSMA-PET/CT, $n(\%)$ & $29(29 \%)$ \\
\hline
\end{tabular}

Abbreviations: $b c P$ biochemical persistence; $b c R$ biochemical recurrence; ISUP International Society of Urological Pathology; $n$ number; $P S A$ prostate-specific antigen; $R P$ radical prostatectomy

Table 2 Treatment characteristics
ADT

Concomitant ADT

$83(83 \%)$

Duration ADT

$<6$ months

$18(18 \%)$

6-12 month

$22(22 \%)$

12-24 month

$17(17 \%)$

$>24$ months

$22(22 \%)$

Unknown

$4(4 \%)$

RT

Dose to prostatic fossa EQD2 $1.5 \mathrm{~Gy}(\mathrm{~Gy})$, median (range)

$66(60-70)$

Dose to local recurrence EQD2 $2_{1.5}$ Gy $(\mathrm{Gy})$, median (range)

$70(66-72)$

Dose to lymphatic pathways EQD2 $1.5 \mathrm{~Gy}(\mathrm{~Gy})$, median (range)

$47.5(42.4-50.9)$

Dose to PET-pos. lymph nodes EQD2 $1.5 \mathrm{~Gy}(\mathrm{~Gy})$, median (range)

$65.1(56-66)$

Abbreviations: $A D T$ androgen deprivation therapy; $R T$ radiotherapy 
Fig. 1 Kaplan-Meier curves: BRFS (A), BRFS for ADT vs. no ADT (B), and BRFS for pelvic lymph nodes vs. paraaortic ( \pm pelvic) lymph nodes $(\mathbf{C})$
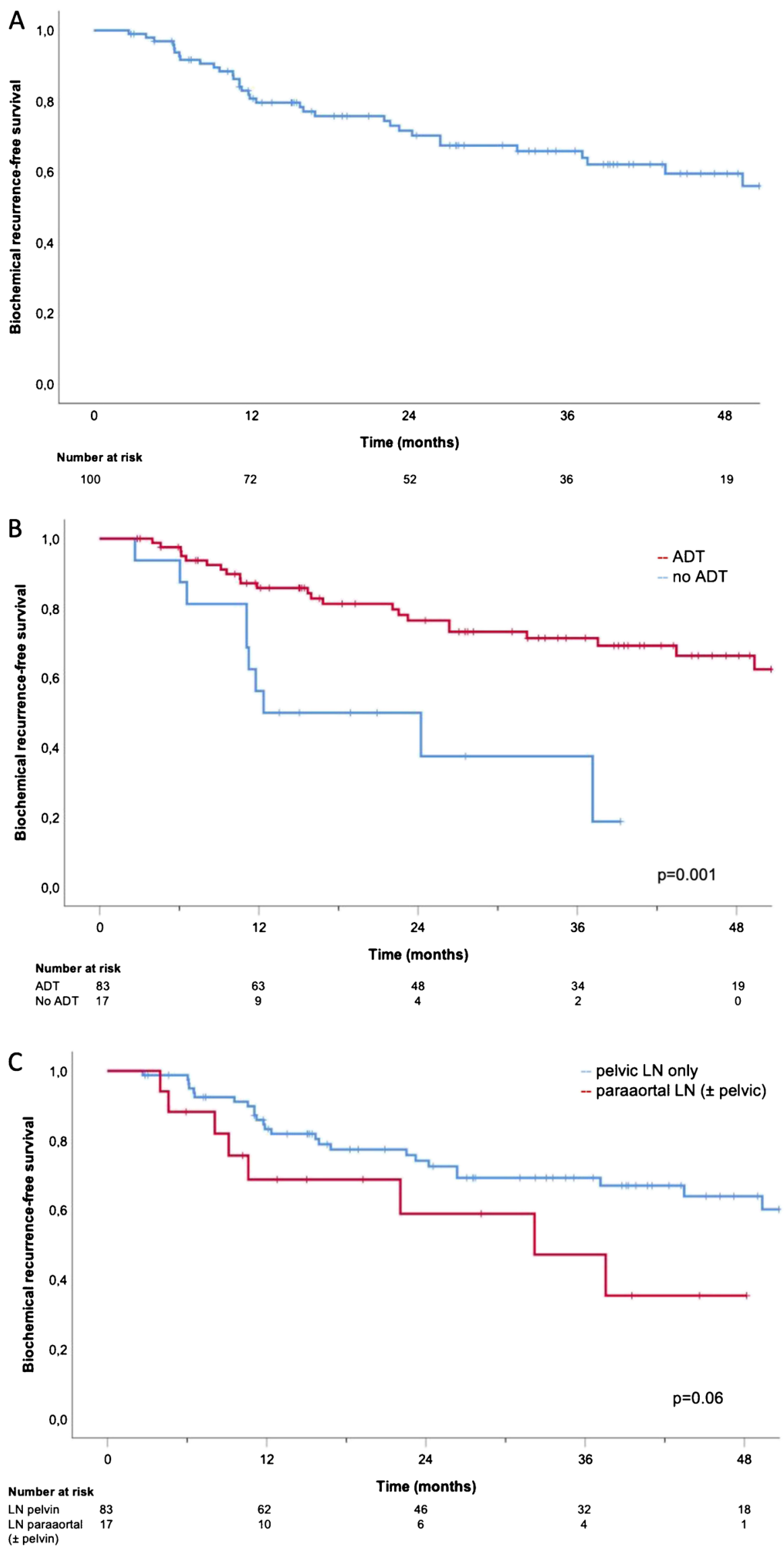
Fig. 2 Kaplan-Meier curves: DMFS (A), DMFS for ADT vs. no ADT (B), and DMFS for PSA pre-sRT $<1 \mathrm{vs.} \geq 1 \mathrm{ng} /$ $\mathrm{ml}(\mathbf{C})$
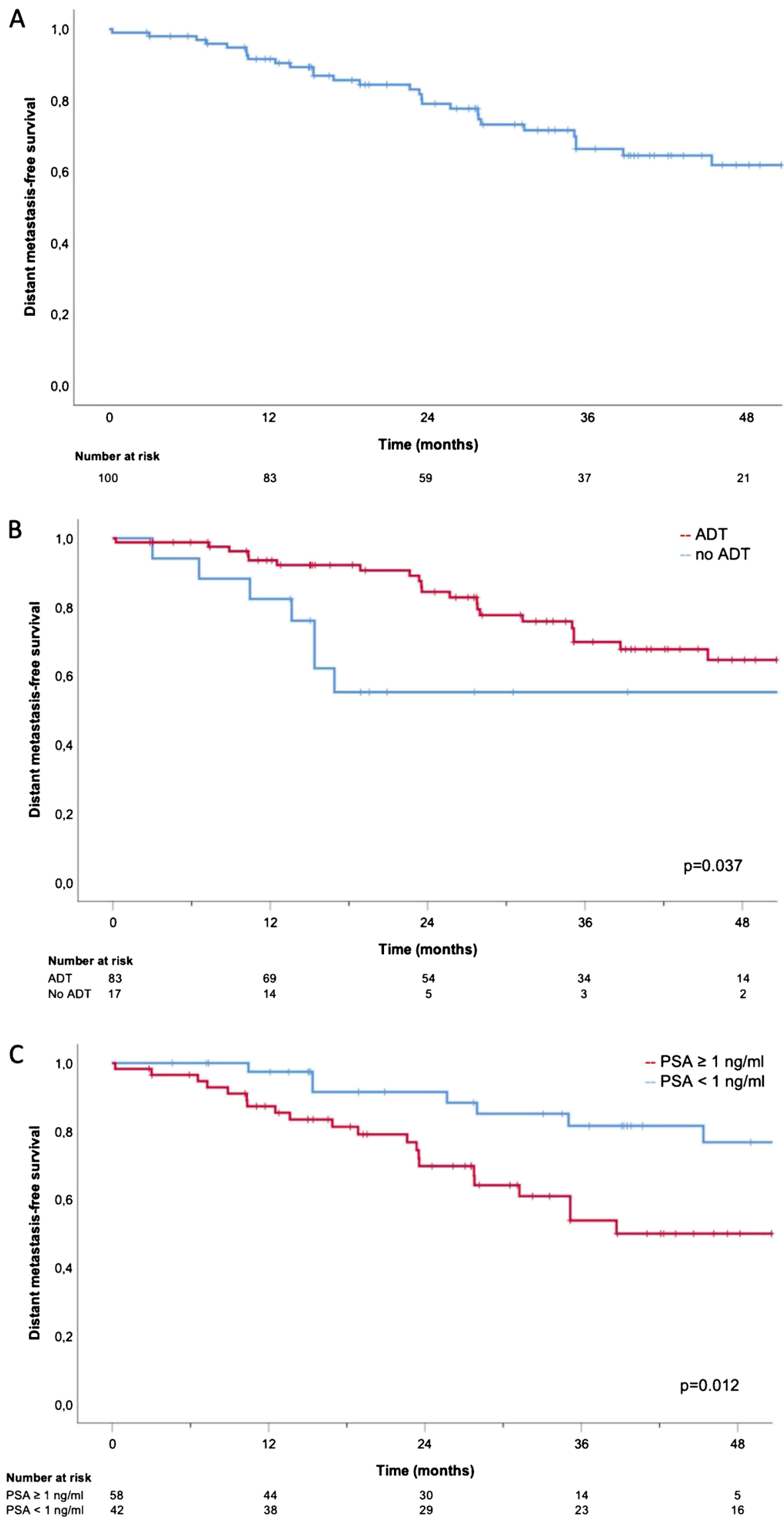
Table 3 Uni- and multivariate analysis for factors associated with BRFS

\begin{tabular}{|c|c|c|c|c|c|}
\hline \multirow[t]{2}{*}{ Patient characteristics } & \multirow[t]{2}{*}{$n$} & \multicolumn{2}{|l|}{ Univariate } & \multicolumn{2}{|l|}{ Multivariate } \\
\hline & & Median BRFS & $\mathrm{p}$-value & $\mathrm{HR}(95 \% \mathrm{CI})$ & $p$-value \\
\hline ISUP score & & & 0.580 & $1.09(0.45-2.63)$ & 0.854 \\
\hline$\leq 3$ & 39 & NR & & & \\
\hline$\geq 4$ & 61 & NR & & & \\
\hline Initial tumor stage & & & 0.367 & $2.06(0.51-8.24)$ & 0.308 \\
\hline$\leq \mathrm{T} 2$ & 21 & NR & & & \\
\hline$\geq \mathrm{T} 3$ & 79 & NR & & & \\
\hline Initial nodal stage & & & 0.538 & $0.90(0.40-2.03)$ & 0.798 \\
\hline No & 54 & NR & & & \\
\hline N1 & 42 & NR & & & \\
\hline Number of lymph node metastases & & & 0.277 & $1.47(0.87-2.49)$ & 0.147 \\
\hline 1 & 35 & NR & & & \\
\hline 2 & 23 & NR & & & \\
\hline$\geq 3$ & 42 & NR & & & \\
\hline Lymph node localization & & & 0.060 & $2.97(1.10-8.04)$ & $\mathbf{0 . 0 3 2}$ \\
\hline Pelvic & 83 & NR & & & \\
\hline Paraaortic $( \pm$ pelvic $)$ & 17 & 32.2 & & & \\
\hline Concomitant ADT & & & 0.001 & $0.26(0.09-0.76)$ & 0.013 \\
\hline present & 83 & NR & & & \\
\hline Absent & 17 & 12.4 & & & \\
\hline ADT duration & & & 0.021 & $0.28(0.11-0.73)$ & 0.009 \\
\hline$\leq 12$ months & 40 & 37.2 & & & \\
\hline$>12$ months & 39 & NR & & & \\
\hline PSA persistence vs. PSA recurrence & & & 0.17 & $1.78(0.47-6.74)$ & 0.396 \\
\hline PSA persistence & 76 & NR & & & \\
\hline PSA recurrence & 22 & NR & & & \\
\hline PSA before sRT & & & 0.027 & $1.92(0.81-4.57)$ & 0.140 \\
\hline$<1 \mathrm{ng} / \mathrm{ml}$ & 42 & NR & & & \\
\hline$\geq 1 \mathrm{ng} / \mathrm{ml}$ & 58 & NR & & & \\
\hline Local recurrence & & & 0.336 & $1.14(0.48-2.72)$ & 0.767 \\
\hline No local recurrence & 71 & NR & & & \\
\hline Local recurrence & 29 & 37.6 & & & \\
\hline
\end{tabular}

Abbreviations: $A D T$ androgen deprivation therapy; $C I$ confidence interval; $H R$ hazard ratio; ISUP International Society of Urological Pathology; NR not reached; PSA prostate-specific antigen; $s R T$ salvage radiotherapy

Bold values denote statistical significance at the $p<0.05$ level
[16]. In 2018, Tran et al. retrospectively analyzed 53 patients with pelvic or paraaortic LN recurrence. They described a 5-year BRFS of $42 \%$. In contrast to the present analysis, all patients received ADT and RT was based on nowadays fairly outdated ${ }^{11} \mathrm{C}$-acetate or ${ }^{18} \mathrm{~F}$-choline PET/CT [17]. Recently, Ingrosso et al. reported on 41 patients with pelvic LN metastases with a 3-year BRFS of 53\% and a 3-year radiological progression-free survival of $64 \%$. Again, their study differed from the present analysis in regard to a more heterogenous cohort of patients (almost $40 \%$ with RT beforehand), the primarily use of choline PET/CT as staging method, and another definition of PSA relapse (rise to more than $25 \%$ above the PSA value pre-sRT) [18].

The prospective "Oligopelvis-GETUG-P07" phase II trial reported a 2- and 3-year progression-free survival (PFS) of $81 \%$ and $51 \%$, respectively, and a 2- and 3-year BRFS of $58 \%$ and $46 \%$, respectively, in 67 patients with pelvic LN relapse. Consistently with the so far mentioned studies, staging prior to RT was based on choline PET/CT. All patients received 6 months ADT and half of the patients had prior prostate or prostate bed RT. Progression was again defined differently as two consecutive PSA levels above the level at inclusion or clinical progression thus hampering a 
Table 4 Uni- and multivariate analysis for factors associated with DMFS

\begin{tabular}{|c|c|c|c|c|c|}
\hline \multirow[t]{2}{*}{ Patient characteristics } & \multirow[t]{2}{*}{$n$} & \multicolumn{2}{|l|}{ Univariate } & \multicolumn{2}{|l|}{ Multivariate } \\
\hline & & Median DMFS & $p$-value & $\mathrm{HR}(95 \% \mathrm{CI})$ & $p$-value \\
\hline ISUP score & & & 0.929 & $1.45(0.56-3.71)$ & 0.442 \\
\hline$\leq 3$ & 39 & NR & & & \\
\hline$\geq 4$ & 61 & NR & & & \\
\hline Initial tumor stage & & & 0.456 & $1.02(0.26-4.08)$ & 0.978 \\
\hline$\leq \mathrm{T} 2$ & 21 & NR & & & \\
\hline$\geq \mathrm{T} 3$ & 79 & NR & & & \\
\hline Initial nodal stage & & & 0.685 & $0.75(0.32-1.73)$ & 0.491 \\
\hline No & 54 & NR & & & \\
\hline N1 & 42 & NR & & & \\
\hline Number of lymph node metastases & & & 0.447 & $1.21(0.72-2.02)$ & 0.469 \\
\hline 1 & 35 & NR & & & \\
\hline 2 & 23 & 54.8 & & & \\
\hline$\geq 3$ & 42 & 53.9 & & & \\
\hline Lymph node localization & & & 0.276 & $1.39(0.49-3.93)$ & 0.534 \\
\hline Pelvic & 83 & NR & & & \\
\hline Paraaortic $( \pm$ pelvic $)$ & 17 & 32.2 & & & \\
\hline Concomitant ADT & & & $\mathbf{0 . 0 3 7}$ & $0.25(0.07-0.89)$ & $\mathbf{0 . 0 3 3}$ \\
\hline Present & 83 & NR & & & \\
\hline Absent & 17 & 12.4 & & & \\
\hline ADT duration & & & 0.342 & $0.84(0.35-2.03)$ & 0.693 \\
\hline$\leq 12$ months & 40 & NR & & & \\
\hline$>12$ months & 39 & NR & & & \\
\hline PSA persistence vs. PSA recurrence & & & 0.152 & $2.26(0.51-9.90)$ & 0.281 \\
\hline PSA persistence & 76 & 61.6 & & & \\
\hline PSA recurrence & 22 & NR & & & \\
\hline PSA before sRT & & & 0.012 & $2.56(1.01-6.46)$ & 0.047 \\
\hline$<1 \mathrm{ng} / \mathrm{ml}$ & 42 & NR & & & \\
\hline$\geq 1 \mathrm{ng} / \mathrm{ml}$ & 58 & 38.7 & & & \\
\hline Local recurrence & & & 0.285 & $0.90(0.37-2.19)$ & 0.814 \\
\hline No local recurrence & 71 & NR & & & \\
\hline Local recurrence & 29 & 45.4 & & & \\
\hline
\end{tabular}

Abbreviations: $A D T$ androgen deprivation therapy; $C I$ confidence interval; $H R$ hazard ratio; ISUP International Society of Urological Pathology; NR not reached; PSA prostate-specific antigen; sRT salvage radiotherapy

Bold values denote statistical significance at the $p<0.05$ level direct comparison [19]. In contrast to the mentioned studies evaluating mainly patients with choline PET/CT-based sENRT [16-19], patients in the present analysis received PSMA-PET/CT-based sENRT which probably explains the comparably good outcomes in this analysis.

Nevertheless, despite the promising results of these analyses, the best therapeutic strategy in patients with LN recurrence is still a matter of debate [26] and data comparing ENRT with other treatment strategies are so far sparse.

A possible treatment strategy could be ADT alone with data from the prospective "Oligopelvis 2-GETUG P12" phase III trial, randomizing patients with LN oligorecurrence between ADT alone and ADT plus PET/CT-based
ENRT, still pending and eagerly awaited. Another possible treatment strategy is SBRT. There is growing evidence for SBRT in patients with LN metastases coming from trials which evaluated SBRT as metastasis-directed therapy (MDT) in oligometastatic PCa and which included patients with nodal oligometastases [27-30]. Moreover, there is a retrospective analysis of SBRT in patients with nodal oligorecurrence [31]. In all these studies, the stereotactic approach showed good local control and low toxicity rates. Nevertheless, compared to ENRT, PFS in these studies seems to be worse with a 2-year PFS between 16 and $58 \%$ mainly triggered by $\mathrm{LN}$ recurrence outside the radiation volume. This has been reconfirmed in a large retrospective analysis with 
more than 500 patients by De Bleser et al. directly comparing SBRT to ENRT in patients with LN recurrence. They analyzed more than 500 patients with nodal oligorecurrence staged mostly by choline PET/CT and treated by either ENRT (with or without SIB) or SBRT. Patients had a significantly worse 3-year metastasis-free survival of $68 \%$ when treated with SBRT compared to $77 \%$ after ENRT [32]. However, a considerable number of patients in the ENRT cohort already had prior ADT (32\%) or prior RT of the prostate, the prostate bed, or the whole pelvis $(66 \%)$ which complicates a direct comparison with our data and might explain the better results. The benefit of a node-based therapeutic approach is currently being analyzed in the prospective randomized "STORM" phase II trial. Patients with pelvic LN oligorecurrence receive MDT with salvage lymph node dissection (sLND) or SBRT plus 6 months of ADT with or without additional ENRT. The study is expected to be completed at the end of 2023 and will further clarify this issue [33]. Furthermore, retrospective data suggest a trend towards a better disease-free survival and a significantly lower ADT administration rate for PSMA-PET/CT-based SBRT compared to choline PET/CT-based SBRT [34].

So far, there is limited evidence that adjuvant ENRT also improves the relapse-free survival in patients treated with sLND compared to sLND alone when staged with choline PET/CT [35]. When comparing in retrospective studies sLND with ENRT in patients with LN recurrence all staged with PSMA-PET/CT, there was an equally higher BRFS in the ENRT cohort $[36,37]$. Therefore, the hitherto mainly short-term oncological data of patients with LN recurrence in the current PSMA-PET/CT era indicate a benefit for a more extensive therapeutic approach as it is the case with ENRT.

In the present PSMA-PET/CT-based ENRT, cohort concomitant use of ADT was a strong predictor not only for better BRFS in uni- and multivariate analysis, but also for improved DMFS. In other studies evaluating PET/ CT-based ENRT in LN recurrence, there was either no effect of concomitant ADT [16, 18] or all patients received ADT $[17,19]$. High-quality prospective data is until now only available for patients with $\mathrm{bcR}$, in whom the real number of patients with possibly $\mathrm{LN}$ recurrence is mainly unknown. Overall, the addition of ADT significantly improved not only BRFS, but also DMFS and even overall survival (OS) in these studies [38-40]. Regarding the duration of ADT, in the present analysis, there was a significant association with better BRFS but not with DMFS. So far, there is no high-quality evidence from prospective studies addressing the question of ADT duration in the setting of postoperative RT. The LOBSTER trial randomizing between 6 and 24 months of concomitant ADT in patients with bcR receiving sRT of the prostate will shed light on this question [41]. Further research is needed to clarify the ideal duration of ADT in the subset of patients with LN metastases and sENRT. Even in that subset of patients, it might make sense to distinguish between patients with different risk profiles, analogous to duration of concomitant ADT in the definitive prostate RT setting. Apart from concomitant ADT, a PSA $<1 \mathrm{ng} / \mathrm{ml}$ prior to sRT correlated with an improved DMFS in uni- and multivariate analysis as well as with an improved BRFS in the univariate analysis. Lower PSA prior to sRT is a well-known factor associated with better BRFS as proven in retrospective studies [42] and as recently shown in three prospective studies on early sRT [43-45]. In other studies explicitly evaluating ENRT in patients with $\mathrm{LN}$ recurrence, the predictive power of the PSA value was either not reported [16, $17,46]$ or did not reach significance in the multivariate analysis [18]. However, a PSA doubling time of less than 3 months at the time of recurrence seems to have a negative impact on the outcome [17].

Regarding BRFS, also the LN localization was a significant predictor in multivariate analysis: paraaortic LN involvement was, as one might expect, associated with a worse outcome. Fodor et al. also observed a significant association between extrapelvic LN metastases and higher clinical relapse rates in patients treated with PET/CT-based sENRT [16]. The observed prognostic relevance reflects in the TNM classification which classifies paraaortic LN involvement already as distant metastases (M1a) [47]. In the present cohort, longer follow-up is probably needed to gain insight into the influence of paraaortic LN metastases on DMFS.

Apart from those mentioned, there were no other significant predictors for BRFS in our analysis. In particular, there was no difference between patients with $b c P$ and $b c R$. Contrary to the present findings, RT indication (bcP vs. bcR) was observed as a viable predictor for a PSA $\leq 0.2 \mathrm{ng} / \mathrm{ml}$ at last follow-up in patients receiving PSMA-PET-guided SRT in a retrospective analysis [22]. Maybe this effect is masked in patients with LN metastases due to their overall worse prognosis. Longer follow-up and more balanced groups will be necessary to further clarify this question also in the present subset of patients.

To our best knowledge, this study is so far the largest analysis reporting on the outcome of PSMA-PET/CT-based sRT using ENRT with SIB to LN metastases in patients with nodal recurrence. A comparatively homogenous patient cohort was analyzed after exclusion of patients with PETpositive bone metastases or previous RT of the prostate or prostatic fossa.

However, the current study is not without limitations mostly due to its retrospective character: Especially, the use and duration of ADT differed between patients in the present analysis mirroring patients' preferences in a realword setting. Furthermore, a median follow-up time of more 
than 3 years is until now not long enough to report on other endpoints, such as cancer-specific survival and OS. Moreover, treatment-related toxicity which needs to be taken into account when choosing a treatment strategy is not reported in this analysis.

\section{Conclusions}

Overall, the present analysis shows that the high rate of treatment modifications due to the so far unmatched sensitivity and specificity of PSMA PET/CT translates in a comparably high 2- and 3-year BRFS of 72\% and $66 \%$ and $2-$ and 3 -year DMFS of $79 \%$ and $66 \%$ after PSMA-PET/CT-based sENRT for patients with PCa LN recurrence. Significant factors for an improved outcome were use of concomitant ADT, duration of concomitant ADT $>12$ months, PSA before $\mathrm{sRT}<1 \mathrm{ng} / \mathrm{ml}$, and the absence of paraaortic LN metastases. As median BRFS and DMFS are still not reached, longer follow-up and above all randomized controlled data is needed to further implement sENRT as treatment in patients with PET-positive $\mathrm{LN}$ recurrence.

Abbreviations ADT: Androgen deprivation therapy; bcP: Biochemical persistence; bcR: Biochemical recurrence; BRFS: Biochemical recurrence-free survival; CT: Computed tomography; CI: Confidence interval; DMFS: Distant metastasis-free survival; ENRT: Elective nodal radiotherapy; HR: Hazard ratio; IMRT: Intensity modulated radiotherapy; ISUP: International Society of Urological Pathology; IGRT: Image-guided radiotherapy; LN: Lymph node; MDT: Metastasis directed therapy; NR: Not reached; $n$ : Number; OS: Overall survival; PFS: Progression free survival; PCa: Prostate cancer; PSA: Prostatespecific antigen; PSMA-PET/CT: Prostate-specific membrane antigen positron emission tomography/computed tomography; RP: Radical prostatectomy; RTOG: Radiation therapy oncology group; RT: Radiotherapy; sENRT: Salvage elective nodal radiotherapy; sLND: Salvage lymph node dissection; sRT: Salvage radiotherapy; SIB: Simultaneous integrated boost; SBRT: Stereotactic body radiotherapy; VMAT: Volumetric arc therapy

Author contribution Conceptualization, P.R., C.T., and N.S.-H.; methodology, M.U., M.Z., H.I., and L.B.; writing-original draft preparation, P.R. and C.T.; writing - review and editing, R.v.B, C.E., A.K., and M.L.; supervision, U.G., P.B., C.S., and C.B..

Funding Open Access funding enabled and organized by Projekt DEAL.

Data availability Research data are stored in an institutional repository and will be shared upon request to the corresponding author.

Code availability Not applicable.

\section{Declarations}

Ethics approval This retrospective analysis was approved by the local ethics committee (LMU 19-361).

Consent to participate Not applicable.

Consent for publication Not applicable.

Conflict of interest The authors declare no competing interests.

Open Access This article is licensed under a Creative Commons Attribution 4.0 International License, which permits use, sharing, adaptation, distribution and reproduction in any medium or format, as long as you give appropriate credit to the original author(s) and the source, provide a link to the Creative Commons licence, and indicate if changes were made. The images or other third party material in this article are included in the article's Creative Commons licence, unless indicated otherwise in a credit line to the material. If material is not included in the article's Creative Commons licence and your intended use is not permitted by statutory regulation or exceeds the permitted use, you will need to obtain permission directly from the copyright holder. To view a copy of this licence, visit http://creativecommons.org/licenses/by/4.0/.

\section{References}

1. Han M, Partin AW, Zahurak M, Piantadosi S, Epstein JI, Walsh PC. Biochemical (prostate specific antigen) recurrence probability following radical prostatectomy for clinically localized prostate cancer [eng]. J Urol. 2003. https://doi.org/10.1097/01. ju.0000045749.90353.c7.

2. Roehl KA, Han M, Ramos CG, Antenor JAV, Catalona WJ. Cancer progression and survival rates following anatomical radical retropubic prostatectomy in 3,478 consecutive patients: long-term results [eng]. J Urol. 2004. https://doi.org/10.1097/ 01.ju.0000134888.22332.bb.

3. Alongi F, de Bari B, Franco P, Ciammella P, Chekrine T, Livi L, et al. The PROCAINA (PROstate CAncer INdication Attitudes) Project (Part I): a survey among Italian radiation oncologists on postoperative radiotherapy in prostate cancer [eng]. Radiol Med. 2013. https://doi.org/10.1007/s11547-012-0913-8.

4. Vogel MME, Dewes S, Sage EK, Devecka M, Gschwend JE, Schiller K, et al. Patterns of care for prostate cancer radiotherapy-results from a survey among German-speaking radiation oncologists [eng]. Strahlenther Onkol. 2021. https://doi.org/10. 1007/s00066-020-01738-1.

5. Mottet N, Bellmunt J, Bolla M, Briers E, Cumberbatch MG, de Santis M, et al. EAU-ESTRO-SIOG Guidelines on Prostate Cancer. Part 1: screening, diagnosis, and local treatment with curative intent [eng]. Eur Urol. 2017. https://doi.org/10.1016/j. eururo.2016.08.003.

6. Fendler WP, Calais J, Eiber M, Flavell RR, Mishoe A, Feng FY, et al. Assessment of 68Ga-PSMA-11 PET accuracy in localizing recurrent prostate cancer: a prospective single-arm clinical trial [eng]. JAMA Oncol. 2019. https://doi.org/10.1001/jamaoncol. 2019.0096.

7. Farolfi A, Ceci F, Castellucci P, Graziani T, Siepe G, Lambertini A, et al. 68Ga-PSMA-11 PET/CT in prostate cancer patients with biochemical recurrence after radical prostatectomy and PSA $<0.5 \mathrm{ng} / \mathrm{ml}$. Efficacy and impact on treatment strategy [eng]. Eur J Nucl Med Mol Imaging. 2019. https://doi.org/10. 1007/s00259-018-4066-4. 
8. Schmidt-Hegemann N-S, Eze C, Li M, Rogowski P, Schaefer $\mathrm{C}$, Stief $\mathrm{C}$, et al. Impact of 68Ga-PSMA PET/CT on the radiotherapeutic approach to prostate cancer in comparison to CT: a retrospective analysis [eng]. J Nucl Med. 2019. https://doi.org/ 10.2967/jnumed.118.220855.

9. Fendler WP, Ferdinandus J, Czernin J, Eiber M, Flavell RR, Behr SC, et al. Impact of 68Ga-PSMA-11 PET on the management of recurrent prostate cancer in a prospective single-arm clinical trial [eng]. J Nucl Med. 2020. https://doi.org/10.2967/ jnumed.120.242180.

10. Ceci F, Castellucci P, Graziani T, Farolfi A, Fonti C, Lodi F, et al. 68Ga-PSMA-11 PET/CT in recurrent prostate cancer: efficacy in different clinical stages of PSA failure after radical therapy [eng]. Eur J Nucl Med Mol Imaging. 2019. https://doi. org/10.1007/s00259-018-4189-7.

11. Ceci F, Bianchi L, Borghesi M, Polverari G, Farolfi A, Briganti A, et al. Prediction nomogram for 68Ga-PSMA-11 PET/CT in different clinical settings of PSA failure after radical treatment for prostate cancer [eng]. Eur J Nucl Med Mol Imaging. 2020. https://doi.org/10.1007/s00259-019-04505-2.

12. Emmett L, Tang R, Nandurkar R, Hruby G, Roach P, Watts JA, et al. 3-year freedom from progression after 68Ga-PSMA PET/ CT-triaged management in men with biochemical recurrence after radical prostatectomy: results of a prospective multicenter trial [eng]. J Nucl Med. 2020. https://doi.org/10.2967/jnumed. 119.235028

13. de Bruycker A, de Bleser E, Decaestecker K, Fonteyne V, Lumen N, de Visschere $\mathrm{P}$, et al. Nodal oligorecurrent prostate cancer: anatomic pattern of possible treatment failure in relation to elective surgical and radiotherapy treatment templates [eng]. Eur Urol. 2019. https://doi.org/10.1016/j.eururo.2018.10.044.

14. Calais J, Czernin J, Cao M, Kishan AU, Hegde JV, Shaverdian N, et al. 68Ga-PSMA-11 PET/CT mapping of prostate cancer biochemical recurrence after radical prostatectomy in 270 patients with a PSA level of less than $1.0 \mathrm{ng} / \mathrm{mL}$ : impact on salvage radiotherapy planning [eng]. J Nucl Med. 2018. https:// doi.org/10.2967/jnumed.117.201749.

15. Schiller K, Stöhrer L, Düsberg M, Borm K, Devecka M, Vogel MME, et al. PSMA-PET/CT-based lymph node atlas for prostate cancer patients recurring after primary treatment: clinical implications for salvage radiation therapy [eng]. Eur Urol Oncol. 2021. https://doi.org/10.1016/j.euo.2020.04.004.

16. Fodor A, Berardi G, Fiorino C, Picchio M, Busnardo E, Kirienko $\mathrm{M}$, et al. Toxicity and efficacy of salvage carbon 11-choline positron emission tomography/computed tomographyguided radiation therapy in patients with lymph node recurrence of prostate cancer [eng]. BJU Int. 2017. https://doi.org/10.1111/ bju. 13510 .

17. Tran S, Jorcano S, Falco T, Lamanna G, Miralbell R, Zilli T. Oligorecurrent nodal prostate cancer: long-term results of an elective nodal irradiation approach [eng]. Am J Clin Oncol. 2018. https:// doi.org/10.1097/COC.0000000000000419.

18. Ingrosso G, Mariucci C, Tenti MV, Bini V, Alì E, Saldi S, et al. Salvage radiotherapy in patients affected by oligorecurrent pelvic nodal prostate cancer [eng]. Clin Transl Oncol. 2020. https://doi. org/10.1007/s12094-020-02364-0.

19. Supiot S, Vaugier L, Pasquier D, Buthaud X, Magné N, Peiffert D, et al. OLIGOPELVIS GETUG P07, a multicenter phase II trial of combined high-dose salvage radiotherapy and hormone therapy in oligorecurrent pelvic node relapses in prostate cancer [eng]. Eur Urol. 2021. https://doi.org/10.1016/j.eururo.2021.06.010.

20. World Medical Association Declaration of Helsinki. ethical principles for medical research involving human subjects [eng]. JAMA. 2013. https://doi.org/10.1001/jama.2013.281053.

21. Weineisen M, Simecek J, Schottelius M, Schwaiger M, Wester H-J. Synthesis and preclinical evaluation of DOTAGA-conjugated
PSMA ligands for functional imaging and endoradiotherapy of prostate cancer [eng]. EJNMMI Res. 2014. https://doi.org/10. 1186/s13550-014-0063-1.

22. Schmidt-Hegemann N-S, Fendler WP, Ilhan H, Herlemann A, Buchner A, Stief C, et al. Outcome after PSMA PET/CT based radiotherapy in patients with biochemical persistence or recurrence after radical prostatectomy [eng]. Radiat Oncol. 2018. https://doi.org/10.1186/s13014-018-0983-4.

23 Fendler WP, Eiber M, Beheshti M, Bomanji J, Ceci F, Cho S, et al. 68Ga-PSMA PET/CT: Joint EANM and SNMMI procedure guideline for prostate cancer imaging: version 1.0 [eng]. Eur J Nucl Med Mol Imaging. 2017. https://doi.org/10.1007/ s00259-017-3670-z.

24. Lawton CAF, Michalski J, El-Naqa I, Buyyounouski MK, Lee WR, Menard C, et al. RTOG GU Radiation oncology specialists reach consensus on pelvic lymph node volumes for high-risk prostate cancer [eng]. Int J Radiat Oncol Biol Phys. 2009. https:// doi.org/10.1016/j.ijrobp.2008.08.002.

25. Loi M, Incrocci L, Desideri I, Bonomo P, Detti B, Simontacchi $\mathrm{G}$, et al. Prognostic impact of nodal relapse in definitive prostateonly irradiation [eng]. Radiol Med. 2018. https://doi.org/10.1007/ s11547-018-0888-1.

26. Achard V, Bottero M, Rouzaud M, Lancia A, Scorsetti M, Filippi $\mathrm{AR}$, et al. Radiotherapy treatment volumes for oligorecurrent nodal prostate cancer: a systematic review [eng]. Acta Oncol. 2020. https://doi.org/10.1080/0284186X.2020.1775291.

27. Ost P, Jereczek-Fossa BA, van As N, Zilli T, Muacevic A, Olivier $\mathrm{K}$, et al. Progression-free survival following stereotactic body radiotherapy for oligometastatic prostate cancer treatment-naive recurrence: a multi-institutional analysis [eng]. Eur Urol. 2016. https://doi.org/10.1016/j.eururo.2015.07.004.

28. Kneebone A, Hruby G, Ainsworth H, Byrne K, Brown C, Guo L, et al. Stereotactic body radiotherapy for oligometastatic prostate cancer detected via prostate-specific membrane antigen positron emission tomography [eng]. Eur Urol Oncol. 2018. https://doi. org/10.1016/j.euo.2018.04.017.

29. Pasqualetti F, Panichi M, Sollini M, Sainato A, Galli L, Morganti R, et al. 18FFluorocholine PET/CT-guided stereotactic body radiotherapy in patients with recurrent oligometastatic prostate cancer [eng]. Eur J Nucl Med Mol Imaging. 2020. https://doi.org/ 10.1007/s00259-019-04482-6.

30. Phillips R, Shi WY, Deek M, Radwan N, Lim SJ, Antonarakis ES, et al. Outcomes of observation vs stereotactic ablative radiation for oligometastatic prostate cancer: the ORIOLE phase 2 randomized clinical trial [eng]. JAMA Oncol. 2020. https://doi.org/ 10.1001/jamaoncol.2020.0147.

31. Jereczek-Fossa BA, Fanetti G, Fodor C, Ciardo D, Santoro L, Francia CM, et al. Salvage stereotactic body radiotherapy for isolated lymph node recurrent prostate cancer: single institution series of 94 consecutive patients and 124 lymph nodes [eng]. Clin Genitourin Cancer. 2017. https://doi.org/10.1016/j.clgc.2017.01. 004.

32. de Bleser E, Jereczek-Fossa BA, Pasquier D, Zilli T, van As N, Siva S, et al. Metastasis-directed therapy in treating nodal oligorecurrent prostate cancer: a multi-institutional analysis comparing the outcome and toxicity of stereotactic body radiotherapy and elective nodal radiotherapy [eng]. Eur Urol. 2019. https://doi.org/ 10.1016/j.eururo.2019.07.009.

33. de Bruycker A, Spiessens A, Dirix P, Koutsouvelis N, Semac I, Liefhooghe N, et al. PEACE V - Salvage Treatment of OligoRecurrent nodal prostate cancer Metastases (STORM): a study protocol for a randomized controlled phase II trial [eng]. BMC Cancer. 2020. https://doi.org/10.1186/s12885-020-06911-4.

34. Mazzola R, Francolini G, Triggiani L, Napoli G, Cuccia F, Nicosia L, et al. Metastasis-directed therapy (SBRT) guided by PET-CT $18 \mathrm{~F}-\mathrm{CHOLINE}$ versus PET-CT $68 \mathrm{Ga}$-PSMA in 
castration-sensitive oligorecurrent prostate cancer: a comparative analysis of effectiveness [eng]. Clin Genitourin Cancer. 2021. https://doi.org/10.1016/j.clgc.2020.08.002.

35. Rischke HC, Schultze-Seemann W, Wieser G, Krönig M, Drendel $\mathrm{V}$, Stegmaier P, et al. Adjuvant radiotherapy after salvage lymph node dissection because of nodal relapse of prostate cancer versus salvage lymph node dissection only [eng]. Strahlenther Onkol. 2015. https://doi.org/10.1007/s00066-014-0763-5.

36. Schmidt-Hegemann N-S, Buchner A, Eze C, Rogowski P, Schaefer $\mathrm{C}$, Ilhan $\mathrm{H}$, et al. PSMA-positive nodal recurrence in prostate cancer: salvage radiotherapy is superior to salvage lymph node dissection in retrospective analysis [eng]. Strahlenther Onkol. 2020. https://doi.org/10.1007/s00066-020-01605-z.

37. Kretschmer A, Milow J, Eze C, Buchner A, Li M, Westhofen T, et al. Patient-reported and oncological outcomes of salvage therapies for PSMA-positive nodal recurrent prostate cancer: real-life experiences and implications for future trial design [eng]. Front Oncol. 2021. https://doi.org/10.3389/fonc.2021.708595.

38. Shipley WU, Seiferheld W, Lukka HR, Major PP, Heney NM, Grignon DJ, et al. Radiation with or without antiandrogen therapy in recurrent prostate cancer [eng]. N Engl J Med. 2017. https:// doi.org/10.1056/NEJMoa1607529.

39. Pollack A, Karrison TG, Balogh AG, Low D, Bruner DW, Wefel JS, et al. Short term androgen deprivation therapy without or with pelvic lymph node treatment added to prostate bed only salvage radiotherapy: the NRG Oncology/RTOG 0534 SPPORT Trial. Int J Radiat Oncol Biol Phys. 2018. https://doi.org/10.1016/j.ijrobp. 2018.08.052.

40. Carrie C, Magné N, Burban-Provost P, Sargos P, Latorzeff I, Lagrange J-L, et al. Short-term androgen deprivation therapy combined with radiotherapy as salvage treatment after radical prostatectomy for prostate cancer (GETUG-AFU 16): a 112month follow-up of a phase 3, randomised trial. Lancet Oncol. 2019. https://doi.org/10.1016/S1470-2045(19)30486-3.

41. Berghen C, Joniau S, Laenen A, Devos G, Rans K, Goffin K, et al. 693TiP LOBSTER LOng term Better than Short-TErm ADT with salvage radiotherapy. Ann Oncol. 2020. https://doi.org/10.1016/j. annonc.2020.08.2087.
42. Tendulkar RD, Agrawal S, Gao T, Efstathiou JA, Pisansky TM, Michalski JM, et al. Contemporary update of a multi-institutional predictive nomogram for salvage radiotherapy after radical prostatectomy [eng]. J Clin Oncol. 2016. https://doi.org/10.1200/JCO. 2016.67.9647.

43. Kneebone A, Fraser-Browne C, Duchesne GM, Fisher R, Frydenberg M, Herschtal A, et al. Adjuvant radiotherapy versus early salvage radiotherapy following radical prostatectomy (TROG 08.03/ANZUP RAVES): a randomised, controlled, phase 3, noninferiority trial. Lancet Oncol. 2020. https://doi.org/10.1016/ S1470-2045(20)30456-3.

44. Parker CC, Clarke NW, Cook AD, Kynaston HG, Petersen PM, Catton C, et al. Timing of radiotherapy after radical prostatectomy (RADICALS-RT): a randomised, controlled phase 3 trial. Lancet. 2020. https://doi.org/10.1016/S0140-6736(20)31553-1.

45. Sargos P, Chabaud S, Latorzeff I, Magné N, Benyoucef A, Supiot $\mathrm{S}$, et al. Adjuvant radiotherapy versus early salvage radiotherapy plus short-term androgen deprivation therapy in men with localised prostate cancer after radical prostatectomy (GETUG-AFU 17): a randomised, phase 3 trial. Lancet Oncol. 2020. https://doi. org/10.1016/S1470-2045(20)30454-X.

46. Supiot S, Pasquier D, Buthaud X, Magné N, Beckendorf V, Sargos $\mathrm{P}$, et al. Oligopelvis-GETUG P07: a multicenter phase II trial of combined salvage radiotherapy and hormone therapy in oligorecurrent pelvic node relapses of prostate cancer. JCO. 2020. https://doi.org/10.1200/JCO.2020.38.6_suppl.93.

47. Brierley J, Gospodarowicz MK, Wittekind C, editors. TNM classification of malignant tumours [eng]. Chichester, Hoboken: Wiley; 2017.

Publisher's note Springer Nature remains neutral with regard to jurisdictional claims in published maps and institutional affiliations.

\section{Authors and Affiliations}

\section{Paul Rogowski ${ }^{1}$ (Christian Trapp ${ }^{1} \cdot$ Rieke von Bestenbostel $^{1} \cdot$ Chukwuka Eze $^{1}$ - Ute Ganswindt ${ }^{2} \cdot$ Minglun Li $^{1}$. Marcus Unterrainer ${ }^{3,4}$. Mathias J. Zacherl ${ }^{4}$. Harun Ilhan ${ }^{4}$. Leonie Beyer ${ }^{4}$. Alexander Kretschmer ${ }^{5}$. Peter Bartenstein ${ }^{4}$. Christian Stief ${ }^{5}$. Claus Belka ${ }^{1,6} \cdot$ Nina-Sophie Schmidt-Hegemann ${ }^{1}$}

1 Department of Radiation Oncology, University Hospital, LMU Munich, Marchioninistr. 15, 81377 Munich, Germany

2 Department of Radiation Oncology, University Hospital, Medical University Innsbruck, Innsbruck, Austria

3 Department of Radiology, University Hospital, LMU Munich, Munich, Germany
4 Department of Nuclear Medicine, University Hospital, LMU Munich, Munich, Germany

5 Department of Urology, University Hospital, LMU Munich, Munich, Germany

6 German Cancer Consortium (DKTK), Munich, Germany 